\title{
An Exploratory Study on the Combined Effects of External and Internal Morphology on Load Dissipation in Primate Capitates: Its Potential for an Understanding of the Positional and Locomotor Repertoire of Early Hominins
}

\author{
Gabriele A. Macho ${ }^{a}$ lain R. Spears ${ }^{b}$ Meave G. Leakey ${ }^{d, ~ e ~}$ \\ Daniel J. McColl ${ }^{b}$ Yong Jiang ${ }^{f}$ Richard Abel $^{c}$ Masato Nakatsukasag \\ Yutaka Kunimatsu ${ }^{\mathrm{h}}$

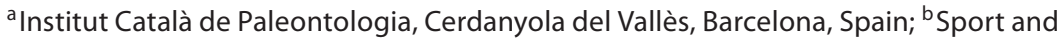 \\ Exercise Subject Group, School of Social Sciences and Law, University of Teesside, \\ Middlesbrough, 'Department of Mineralogy, Natural History Museum, London, UK; \\ ${ }^{\mathrm{d}}$ National Museum of Kenya, Nairobi, Kenya; ${ }^{\mathrm{e}}$ Department of Anthropology, Stony Brook \\ University, Stony Brook, N.Y., USA; ${ }^{f}$ Centre of Sports Mathematics and Engineering, \\ Faculty of Science, Nanjing University of Science and Technology, Nanjing, China; \\ 'Laboratory of Physical Anthropology, Graduate School of Science, Kyoto University, \\ Kyoto, hPrimate Research Institute, Kyoto University, Aichi, Japan
}

\section{Key Words}

Primate capitates - Australopithecus anamensis - Australopithecus afarensis •

Theropithecus oswaldi $\cdot$ Finite element stress analyses $\cdot$ Trabecular bone $\cdot$ Hominin

\begin{abstract}
This pilot study explored whether the redirection of stress through trabeculae within morphologically constrained capitates provides information about habitual/positional behaviours unavailable from the study of external morphology alone. To assess this possibility, an experimental finite element approach was taken, whereby no attempt was made to reconstruct the actual magnitudes and loading conditions experienced by the capitates in vivo. Rather, this work addressed fundamental biological questions relating to bone plasticity, i.e. internal versus external bone morphology. The capitates of 7 species with different and - in the case of fossils - inferred locomotor behaviours were selected. Virtual models of capitates were created, scaled to the same size and subjected to the same theoretical load. In the first set of analyses, models were assigned the material properties of bone throughout, whereas in the second set, models were assigned 11 different material properties representing the trabecular architecture
\end{abstract}

\begin{tabular}{ll}
\hline KARGER & ( ) 2011 S. Karger AG, Basel \\
0015-5713/10/0815-0292\$26.00/0 \\
$\begin{array}{l}\text { Fax +41 61306 1234 } \\
\text { E-Mail karger@karger.ch } \\
\text { www.karger.com }\end{array}$ & $\begin{array}{l}\text { Accessible online at: } \\
\text { www.karger.com/fpr }\end{array}$
\end{tabular}

Gabriele Macho

Institut Català de Paleontologia

Cerdanyola del Vallès, ES-08193 Barcelona (Spain)

E-Mail gabriele.macho@icp.cat 
derived from high-resolution CT. Species with arboreal behaviours consistently redirected loads towards the ulnar aspect of the capitate when trabeculae were introduced, while terrestrial species, and the bipedal Homo, redirected stress towards the radial side. From these preliminary analyses, it is tentatively concluded that Australopithecus anamensis habitually engaged in arboreal behaviours, whereas Australopithecus afarensis did not.

Copyright ๑ 2011 S. Karger AG, Basel

\section{Introduction}

An assessment of locomotor/positional behaviours from isolated bones is difficult due to evolutionary constraints acting on morphology as well as the fact that bone shape reflects both mobility and stability [Rose and Lauder, 1996; Ward, 2002; Macho, 2007]. Evolutionary changes to primate carpals and tarsals appear particularly constrained both phylogenetically and ontogenetically [Dainton and Macho 1999a, b; Tocheri et al., 2007]. The relatively invariant morphometric dimensions of carpals across primates when compared with metacarpals and phalanges [Drapeau and Ward, 2007] is thus unsurprising, as is the apparent temporal lag between behavioural innovation, i.e. tool manufacture and use, and morphological adaptation [Tocheri et al., 2003, 2007]. Nonetheless, the hominin wrist has undergone considerable modifications over its evolutionary past and, while no longer habitually loaded in locomotion, has become adapted to a complex array of power and precision grips necessary for the manipulations required in tool use and manufacture [Marzke, 1997]; anatomical changes in the hominin hand are particularly marked along the radial aspects of the wrist as they relate to more transverse force transmission during power, i.e. spherical 'squeeze', grips [Marzke, 1971, 1997]. What is uncertain is whether the relatively slow evolutionary change in overall bone shape was preceded, or compensated for, by adjustments of the internal bony architecture. This remains a biological possibility given the apparently greater potential of trabeculae for remodelling in response to external loads [Huiskes, 2000]. If so, (palaeo)biomechanical analyses of trabecular bone could provide further insights into the patterns of evolutionary changes observed among early hominins.

Bipedality has apparently been selected for in the earliest hominins. The postcranium of Ardipithecus ramidus suggests terrestrial bipedality with competent use of an arboreal environment [Lovejoy et al., 2009a, b], while the later Australopithecus afarensis had largely abandoned arboreality [White et al., 2006], although some degree of arboreality is still assumed [Ward et al., 2001]. An appraisal of the intermediate chronospecies Australopithecus anamensis, dated between 3.9 and 4.2 million years ago [Leakey et al., 1995, 1998; White et al., 2006], is thus crucial for an understanding of evolutionary pathways, but interpretations are contentious [Leakey et al., 1995; Ward et al., 2001]. The upper limbs, and particularly the capitate, are primitive and it is unclear whether these plesiomorphic characters are a consequence of phylogenetic constraints, have been retained by stabilizing selection or have simply not been selected against. Although resolution of this question will ultimately only come from more complete fossils, insights may also be gleaned from analyses of the internal structure of bones. In order to explore this possibility the capitates of Au. anamensis (KNM-KP 31724) from Kanapoi and of Au. cf. afarensis (KNM-WT 22944) 
from South Turkwel were analysed vis-à-vis capitates of extant primates with different locomotor and positional behaviours. Hence, the goals of this pilot study are twofold. Firstly, the study is of heuristic value and aims to determine whether the load transfer within phylogenetically constrained bones can be determined from overall bone shape alone. Secondly, it addresses the specific question whether the combined effects of external and internal morphology could provide novel insights into the positional and locomotor behaviour of Australopithecus.

\section{Material and Methods}

Four isolated (dry) capitates belonging to Homo, Pan, Gorilla and Pongo were scanned at the University of Liverpool with an ACTIS 420/600 system (slice thickness: $100 \mathrm{~mm}$; increments: $100 \mathrm{~mm}$; matrix size: $512 \times 512$; voltage: $45-55 \mathrm{kV}$; current: $160-200 \mathrm{~mA}$; effective monochromatic X-ray energy: $22.5-27.5 \mathrm{keV}$ ). The available non-human primate specimens, except Pongo, were catalogued unprovenanced or zoo animals, while the Homo capitate is from an archaeological collection [Macho et al., 2005]. As these putative zoo animals are terrestrial quadrupeds [Gebo, 1996], it was deemed acceptable to include them in the analyses: their terrestrial behaviours would not have been compromised by this artificial environment. The capitates of Theropithecus oswaldi (KNM-OG 977) from Olorgesailie, Au. cf. afarensis (KNM-WT 22944) from South Turkwel [Ward et al., 1999] and Au. anamensis (KNM-KP 31724) from Kanapoi [Leakey et al., 1995; Ward et al., 2001] were scanned at the National Museum of Kenya with a portable Stratech pQCT scanner at comparable settings.

From the CT images the capitate-specific half-maximum height values were determined [McColl et al., 2006] and inputted into an algorithm to create an isosurface within the scan (Visual Toolkit, public.kitware.com); these were subsequently inputted into MSc Mentat, the finite element (FE) preprocessor. The isosurfaces were volumetrically meshed, whereby element sizes were gradually reduced from $0.4 \mathrm{~mm}$ (edge length) at $0.1 \mathrm{~mm}$ increments until the ratio of summed reaction forces at the ulnar and radial facets (i.e. the output variable) changed by less than $1 \%$. Optimal element size for the different species was around $0.4 \mathrm{~mm}$ depending on the complexity of the outer surfaces. The final models of Homo, Pan, Gorilla and Pongo were meshed using 99,811,157,432, 94,738 and 102,380 elements, respectively, and the fossil capitate element sizes were 25,996 (KNM-WT 22944), 33,289 (KNM-KP 31724) and 22,584 (KNM-OG 977); mesh sizes also reflect differences in bone size.

\section{Loading Conditions}

Difficulties in accessibility prevent testing of capitates under loading conditions habitually encountered and experimental data on non-human primates are particularly sparse [Jenkins and Fleagle, 1975; Jenkins, 1981]. Also, uncertainty remains as regards the kinematics of knuckle-walking in the African apes [Kivell and Schmitt, 2009]. Nonetheless, the predominant loads in the capitate are proximodistal during grasping [Manal et al., 2002] and in terrestrial locomotion [Jenkins and Fleagle, 1975; Patel, 2010]. This, together with the nearly parallel orientation of the capitate head and the 3rd (and 2nd) metacarpal (MCIII and MCII) implies predominantly compressive loading along the longitudinal axis. Although the magnitudes of forces across the wrist are not known and will depend inter alia on activity and body mass, the mechanism of load transfer (i.e. from head to distal surface) is expected to be the same. Accordingly, all models were scaled to a height of $2 \mathrm{~cm}$, and a theoretical load of $100 \mathrm{~N}$ was applied to the capitate head, and the joint reaction forces (RFs) at the distal facets were recorded. The distal capitate facets were partitioned into ulnar and radial components, following morphological criteria. In the great apes, where the distal facet is occupied by MCIII only, there is a distinct radial cupping, whose functional significance remains unclear [McHenry, 1983]. In Homo, Theropithecus and $\mathrm{Au}$. afarensis, the MCII facet has shifted - to varying degrees - onto the distal aspect of the capitate to facilitate increased manipulation [Marzke, 1997; Ward et al., 1999]. In 


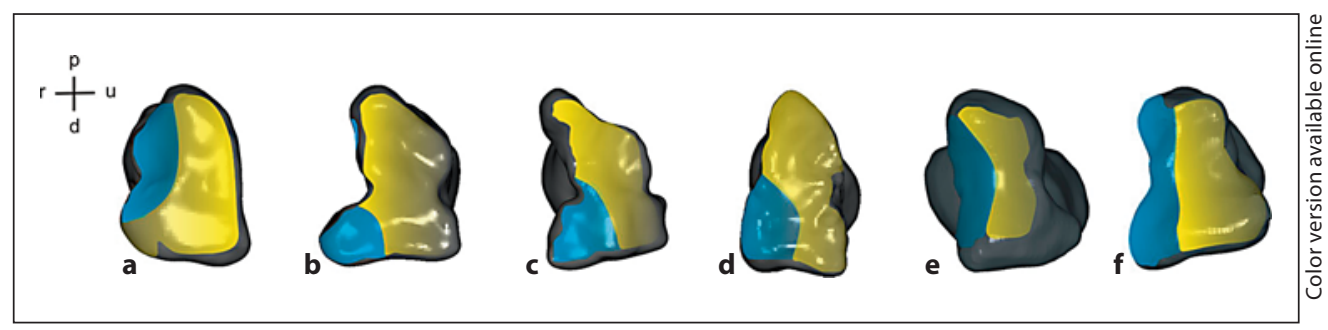

Fig. 1. Distal view of the scaled capitates. a Homo sapiens. b Pan troglodytes. c Pongo pygmaeus. d Gorilla gorilla. e Australopithecus cf. afarensis (KNM-WT 22944). f Theropithecus oswaldi (KNM-OG 977). $\mathrm{r}=$ radial; $\mathrm{p}=$ proximal; $\mathrm{u}=$ ulnar; $\mathrm{d}=$ distal. Blue denotes the radial aspect analysed and yellow the ulnar one (colours in the online version only). Because of the assumptions made (although not affecting the internal stress flow), the outline for KNM-KP 31724 is not shown.

Au. anamensis, the MCII facet is at a 90-degree angle to MCIII and resembles the morphology of the great apes, but there is some cupping of the MCIII facet also. Due to weathering and surface damage, delineation of these cuppings is difficult, while the overall orientation of the distal facet is somewhat inclined (because of abrasion) compared to what it would have been in vivo. It is acknowledged that these limitations will affect the absolute RFs. However, the stress flow along trabeculae within the bone is unlikely to be affected, and an assessment of the potential effects of trabeculae on load transfer, i.e. redirection, thus seems valid. In all models, the laterally facing joint surfaces (e.g. primate MCII facets, human MCIII styloid process) were constrained also but, owing to their orientation relative to the axial loading direction (i.e. normal), no RFs were obtained; where these facets were slightly less/more than $90^{\circ}$, some small RFs were obtained, but these values were negligible and were thus not analysed further. Distal joint facets (fig. 1) were held fixed and the resulting RFs were used to quantify the load distribution. The summed RFs in the $\mathrm{x}-$, $\mathrm{y}$ - and $\mathrm{z}$-directions at each facet were subsequently divided by facet area to calculate mean facet stress. The results for the homogeneous model were compared with those of the heterogeneous model to appraise the redistribution of stress through trabeculae. Across the primate models, the distal partitionings differ in size, relate to either 2 aspects of MCIII or to MCII and MCIII, respectively, and are reconstructed in KNM-KP 31724. Consequently, direct comparisons of RFs would not be valid (i.e. meaningful, comparable), and only the percentage differences between homogeneous and heterogeneous models are interpreted here. The proportional redirection of loads as a consequence of trabecular architecture is deemed a meaningful measure for (palaeo)biological and (palaeo)biomechanical enquiry.

For each species, 2 models were created. The first set was assigned homogeneous material properties throughout (i.e. solid); bone was considered homogeneous, isotropic and linearly elastic $\left(\mathrm{E}_{\mathrm{tissue}}=25 \mathrm{GPa}\right.$ and $\left.\mathrm{n}=0.3\right)$ [Turner et al., 1999]. These homogeneous models enabled quantification of stress distribution under compressive loading based on overall shape alone. The second models were assigned heterogeneous material properties and contain information about both the external shape and internal morphology. When compared with the homogeneous models, differences in stress distribution are considered to represent the effects of trabecular architecture; differences in morphological adaptation (adaptability) of overall bone shape vis-à-vis trabecular architecture can thus be assessed.

\section{Material Model Calibration and Validation}

For extant species, micromodels of trabecular cubes were created in high-resolution polygon and low-resolution voxel form. The former provide benchmark data while the latter are calibrated against these data to determine an appropriate conversion from CT numbers to material stiffness. For this purpose, cubes of trabecular bone from the capitate head of Homo, Pan, 


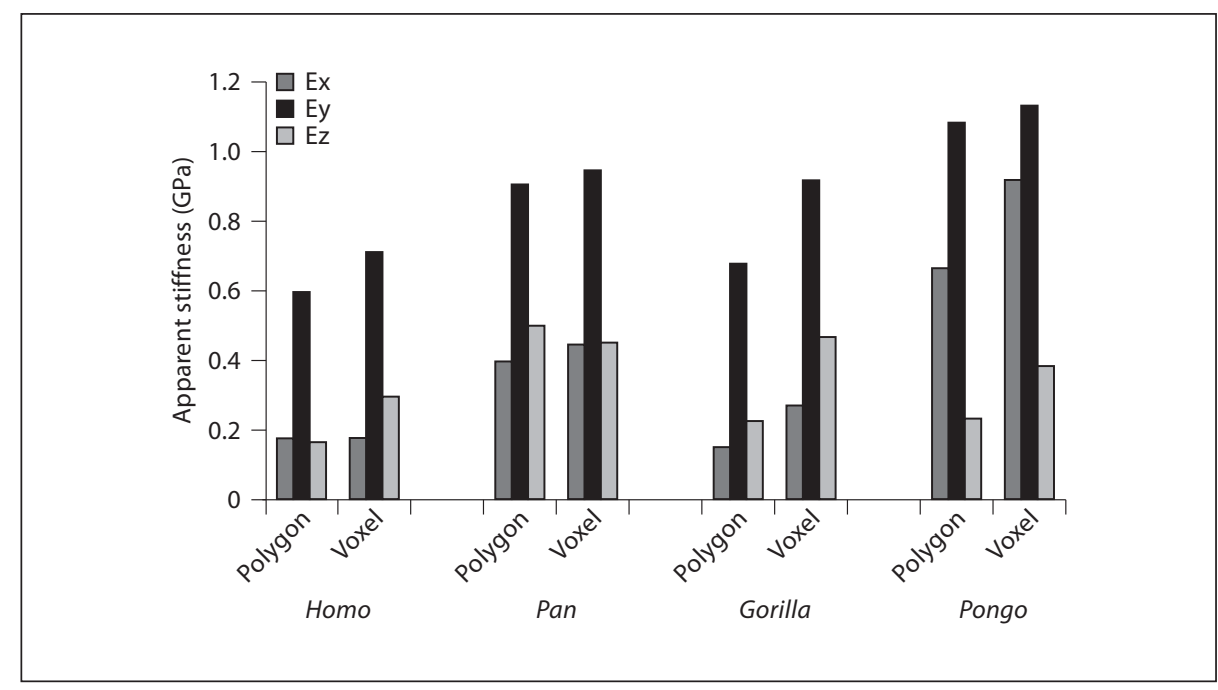

Fig. 2. Shown are the apparent stiffness values in the $\mathrm{x}$-direction (Ex; mediolateral), $\mathrm{y}$-direction (Ey; proximodistal) and z-direction (Ez; dorsopalmar) for the thresholded voxel-based and polygon-based models for extant primates.

Gorilla and Pongo were extracted $(4 \times 4 \times 4 \mathrm{~mm}$ each). For all cubes, the bone-air interface was calculated for each pixel row [McColl et al., 2006] and checked for normal distribution. Using Visual Toolkit (www.kitware.com), an isocontouring value equal to the respective mean half-maximum height values was used to extract polygon surfaces of trabeculae. The surfaces were meshed volumetrically using tetrahedral elements with an average element size of $0.12 \mathrm{~mm}$ [Kabel et al., 1999]. This ensured at least 2 internal nodes across any trabeculae. Bone within these models was considered homogeneous, isotropic and linearly elastic $\left(\mathrm{E}_{\text {tissue }}=25 \mathrm{GPa}, \mathrm{n}=\right.$ $0.3)$. Voxel-based models $(10 \times 10 \times 10$ elements $)$ of the same regions were then created using an element size of $0.4 \mathrm{~mm}$, comparable to the average trabecular thickness $(0.45 \mathrm{~mm})$ in the human capitate [Macho et al., 2005]. All models were subjected to the same displacement-controlled unconfined compression (strain $=0.1 \%$ ) along their 3 primary axes in order to determine apparent stiffness. In the voxel-based models, the mean half-maximum height was chosen as the threshold above which the CT numbers ('possible bone') were separated into 10 equally spaced bands of linearly increasing stiffness. Following preliminary tests, the number of material bands was gradually increased until no further changes (i.e. less than 5\%) in calculated apparent stiffness occurred and a comparable level of anisotropy was maintained between the voxel and polygon models. This was achieved when the high stiffness band was increased to $50 \%$.

Despite some minor differences in comparability between models (fig. 2), it was deemed appropriate to settle for a common conversion factor (i.e. 11 materials) across all models, including fossils. Mechanical tests (MTS Systems Corporation, Eden Prairie, Minn., USA) were then performed on a dry, apparently male capitate (unprovenanced) held within the teaching collection of the Department of Human Anatomy, University of Liverpool. The bone was fixed to a clamp, and a hemispherical stainless-steel indenter $(2 \mathrm{~cm}$ diameter $)$ was attached to the load cell. The indenter was polished smooth to minimize friction during testing and attached to the 10 Newton load cell and actuator. Indentations up to $0.05 \mathrm{~mm}$ were applied to the specimen in both proximal-distal and medial-lateral directions with a speed of $0.1 \mathrm{~mm} / \mathrm{s}$. The Homo capitate model, created following the conversion algorithm outlined above, was then subjected to an 

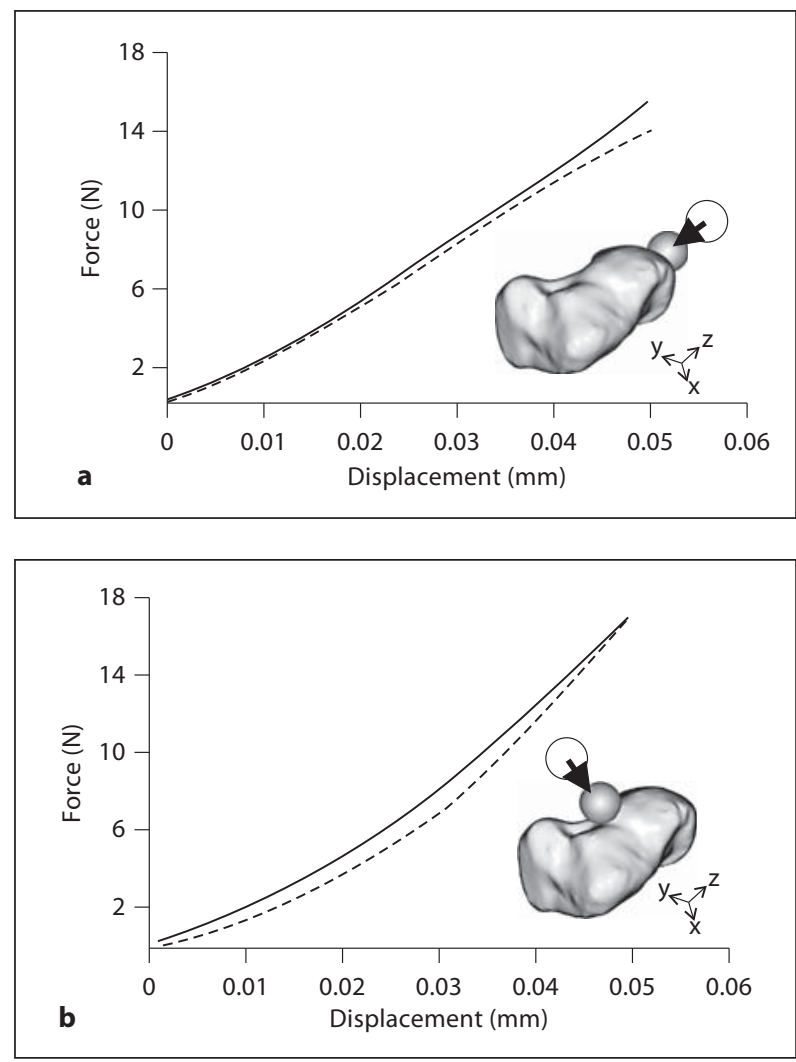

Fig. 3. Uni-axial force-displacement curves recorded in vitro (solid line) for a modern human capitate and the corresponding FE model (stippled line) for proximodistal (a) and mediolateral (b) loading.

identical loading regime and the force-displacement curves were compared (fig. 3). Overall, the external behaviour of the model was similar to the real capitate, although slightly less stiff under the lower loads when applied medial-laterally.

\section{Limitations}

Sample sizes of this exploratory study are small and are limited by the assignment of material properties to the thin outer cortical shell of capitates, which has to be done manually: the $\mathrm{CT}$ numbers at the interface cannot be automatically converted due to volume-averaging effects, which makes the creation of the models very time consuming. Also, (our) computational limitations restrict the structural detail (i.e. number of elements) required to predict local stress values within trabeculae [Ryan and van Rietbergen, 2005]. Accordingly, these predictions are not made here, and load redistribution is the reported parameter. Perhaps the limitations with the greatest potential influence for assessing the actual behaviour of capitates under load are the material properties used: data were taken from the literature and adapted. They were calibrated locally with data derived using high-resolution structural models and confirmed globally with data from dry bone under mechanical compression. No in vivo testing was carried out, and anisotropy was assumed to result from architectural fabric alone. 

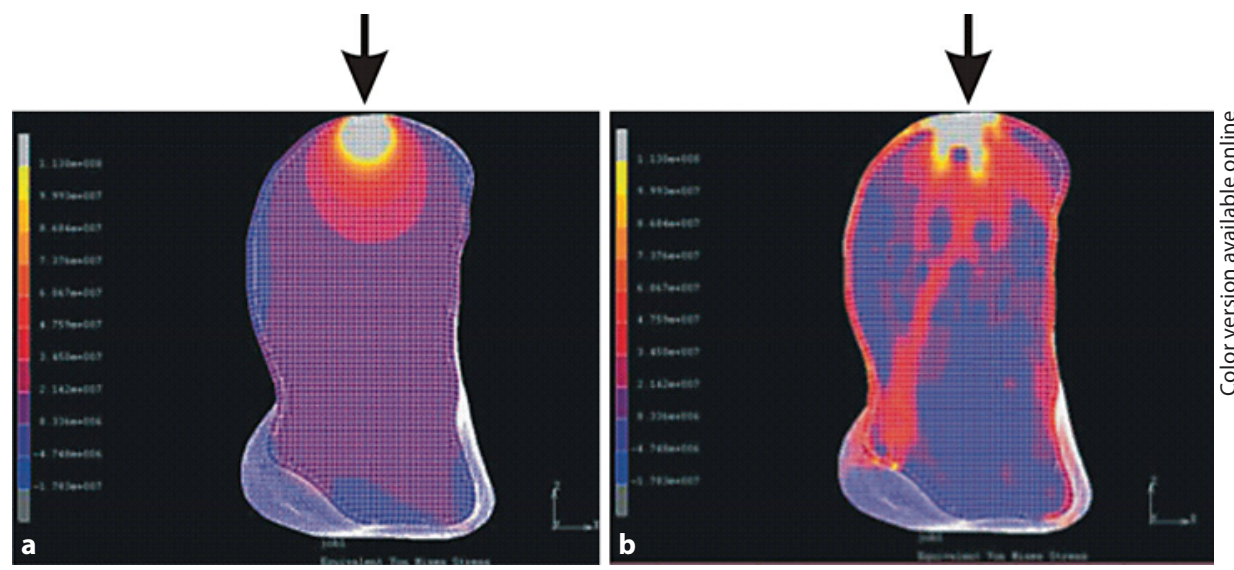

Fig. 4. Cross-section through the Homo capitate to illustrate the stress flow (van Mises stresses) for the homogeneous (a) and heterogeneous (b) models. The joint surfaces at the distal end (bottom) were constrained, and a point load was applied to the capitate head (arrow). The radial aspect of the capitate is towards the left and the ulnar towards the right.

The models are simplistic representations of in vivo capitate biomechanics. For example, it has been suggested that the waisted neck of the capitate in Pan and Gorilla (shared by Au. cf. afarensis [Ward et al., 1999]) forms part of a close packing mechanism at the mid-carpal joint, whereby the scaphoid rotates around the capitate head to fit into the neck, thus preventing further extension. This could provide stability at the mid-carpal joint during suspensory locomotor behaviour [Lewis, 1972] or may prevent wrist collapse during knuckle-walking [Tuttle, 1967, 1969]. Whatever the functional significance, such a stabilizing mechanism would exert a palmarly directed force on the capitates, a force not incorporated in the loading regime of this study. Also, while it is reasonable to suggest that the capitate is mainly loaded proximodistally in compression, the actual loading during different behaviours may vary [Manal et al., 2002; Patel, 2010]. Differences in body mass were not taken into account either, nor were possible sexrelated differences in behaviour.

\section{Results and Discussion}

The mechanical and anisotropic behaviour of carpals is determined by their external shape, which forms a thin shell, and their complex trabecular arrangement. Trabecular bone is often considered to be particularly plastic and to respond to external loads [Huiskes, 2000]. However, recent studies have highlighted the (presumably genetic) predetermination of trabecular strut development in utero [Volpato, 2008; Cunningham and Black, 2009a, b]. Furthermore, like subchondral bone density and organization, trabecular bundle orientation appears to reflect positional [Carlson and Patel, 2006; Abel and Macho, 2011] rather than locomotor behaviour [Ryan and van Rietbergen, 2005; Volpato et al., 2008]. Against this background, it was explored whether biomechanical analyses of internal and external bone arrangement yield comparable results to those derived from analyses of external bone alone. 


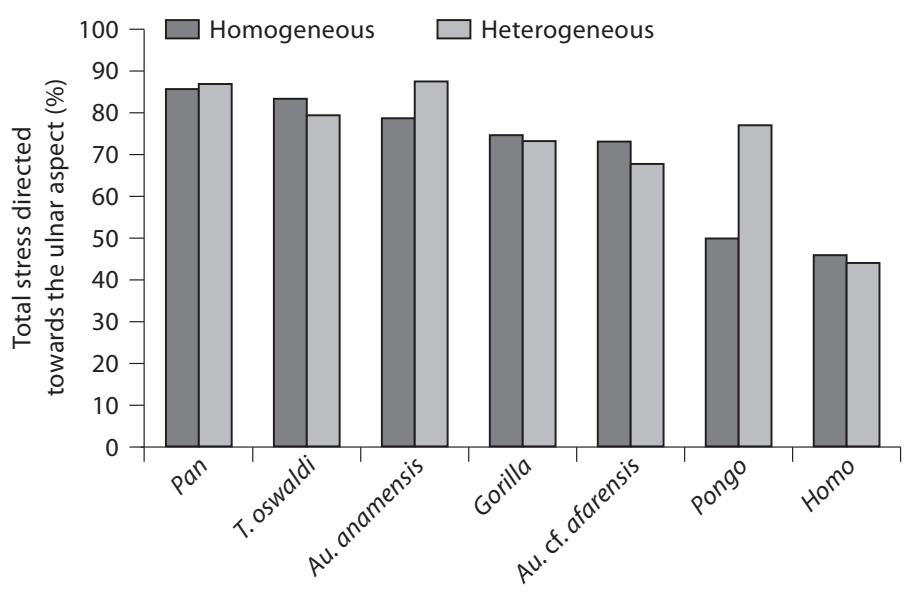

Fig. 5. Percentage of total stress directed towards the ulnar aspect of the distal capitate surface for homogeneous and heterogeneous models.

In Homo the highest proportion of force (55\%) is transmitted onto the capitate's radial aspect (fig. 4, 5), while in non-human primates the ulnar aspect of the distal facet generally shows the highest overall RFs [Schmitt, 2003]. This finding is expected from morphological considerations alone, i.e. the incorporation of the MCII articulation onto the distal capitate surface in modern humans. However, the relatively great disparity between homogeneous and heterogeneous models, when compared to Pan (0.6\%) and Gorilla (1.4\%), is unexpected (fig. 4). It is probable that this $2.5 \%$ differential between homogeneous and heterogeneous models in Homo (fig. 5, 6) reflects the relatively late acquisition of modern human wrist anatomy. Indirect evidence for a still incomplete adaptation comes from observations that the most common degenerative disorders in the modern human hand and wrist collapse are radial-sided [Taniguchi et al., 2003]. In contrast, the great ape capitates appear well designed, whereby the introduction of trabeculae resulted in only small changes in load transfer. The overall results between species, as well as the subtle differences between homogeneous and heterogeneous models, are however meaningful with regard to both behaviour and phylogeny.

The African apes share a unique mode of terrestrial locomotion, but the kinematics of their knuckle-walking behaviours differs [Inouye, 1994; Kivell and Schmitt, 2009]. Importantly, gorillas spend more time in terrestrial locomotion, in part due to their larger body mass [Inouye, 1994], whereas chimpanzees are more arboreal. The results of this FE study can be interpreted within the context of these behavioural differences. Of all species analysed, Pan transmits the greatest proportion of stress towards the ulnar component of the distal capitate facet, and this trend is exacerbated even further when the effects of trabeculae are taken into account 


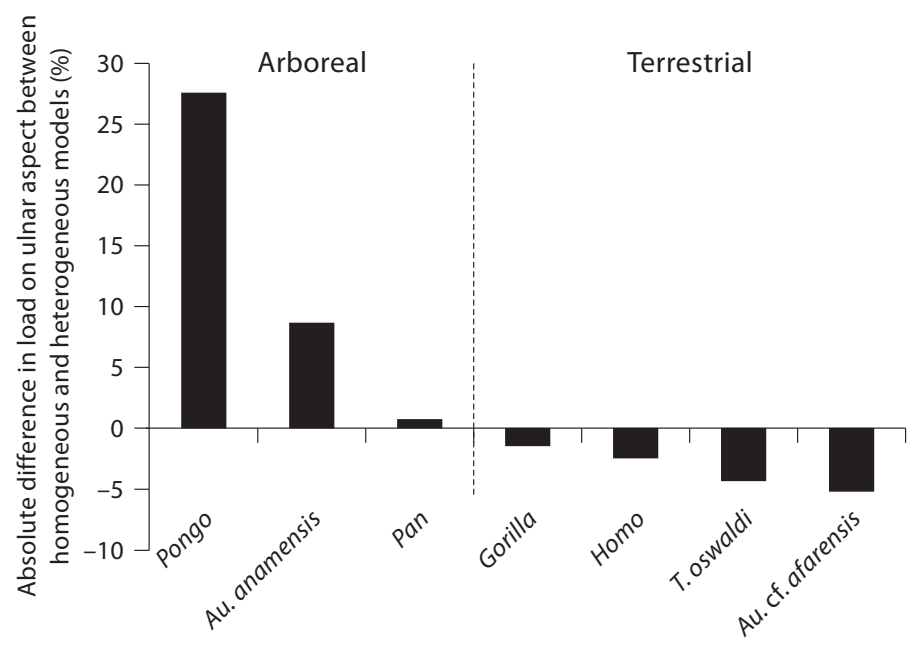

Fig. 6. The percentage difference between the respective homogeneous and heterogeneous models. Arboreal species apparently redirect load towards the ulnar aspect when trabeculae are introduced into the models, while terrestrial species redirect the load towards the radial side.

(fig. 5, 6). Contrarily, Gorilla concentrates proportionally less stress on the ulnar component of the MCIII facet and, importantly, redirects stress towards the radial side when trabeculae are taken into account (fig. 6). This pattern of overall force transmission is in line with observations that gorillas transmit forces more equally through metacarpals II-IV than chimpanzees [Inouye, 1994]. The ulnar redirection of loads through trabeculae in chimpanzees, but not in gorillas, is conceivably indicative of the greater arboreal behaviour of the former. This interpretation is based on the results for Pongo. Although the positional and locomotor behaviours of the orang-utan, as well as the overall joint morphologies of its wrist, are highly specialized [Sarmiento, 1988], there are commonalities which allow such inferences to be made (and even though the results for Pan are limited).

The hand of Pongo is adapted to a high degree of rotational movement necessary for movement in the canopy despite its large body size. In quadrumanous behaviour, the orang-utan may load the wrist proximodistally in suspension (but see Cartmill and Milton [1979]) as it does in terrestrial locomotion, such as fist or knuckle-walking [Tuttle, 1967]. During vertical climbing, however, the hand is apparently loaded in compression while adducted [Rose, 1988]. The extreme redirection of stress towards the ulnar aspect of the bone thus appears to compensate for constraints imposed by overall bone shape necessary to accommodate movement. The capitate of the orang-utan may thus reflect a compromise between two very different loading conditions. Although further analyses are clearly needed to ultimately clarify this issue, the consistency between stress patterns and arboreal versus terrestrial behaviours is remarkable (fig. 6) and may shed some light on the behaviour of extinct 
hominins, while the pattern found in T. oswaldi is consistent with interpretations of a terrestrial primate with unique manipulatory capabilities.

In Theropithecus, an improvement in manipulation to facilitate the unique feeding behaviour [Jablonski, 1993] apparently underlies the shift of the MCII facet onto the distal aspect of the capitates and may explain the relatively high percentage difference between T. oswaldi models, similar to modern humans (fig. 6). Yet, unlike Homo, the total proportion of stress directed towards the ulnar side of the theropith capitate (approx. 80\%) almost certainly reflects the species' quadrupedal locomotion and positional behaviour [Jolly, 1972; Ciochon, 1994]. This is in accord with experimental studies on the loading of the forelimb in cercopithecids that revealed ulnarly directed ground RFs during quadrupedal walking [Schmitt, 2003]. Although experimental data are not available for extant Theropithecus, it is reasonable to infer that the high percentage of ulnarly directed load observed in the capitate of T. oswaldi, and its relative position between Pan and Gorilla in overall values (fig. 5), reflects the species' terrestrial quadrupedalism. Conversely, the patterns found in the extinct hominins analysed here do not suggest loading of the wrist in terrestrial locomotion.

Morphological differences between the capitates of Au. cf. afarensis (KNM-WT 22944) and $A u$. anamensis (KNM -KP 31724) are considerable and suggest that the former species had abandoned arboreality, whereas the latter had not [Leakey et al., 1995; Ward et al., 2001]. Although the MCII joint surface of the Au. anamensis capitate is apparently continuous, as in later hominins, it is radially orientated, as in apes. To what extent this plesiomorphic feature has been retained by stabilizing selection remains unclear however. The results of the FE analyses for the Au. anamensis capitate mirror the pattern of load transfer, i.e. redirection, found in the highly arboreal orang-utan and, to a far lesser extent, the partially arboreal chimpanzee (fig. 6). Hence, both the external morphology and the internal structure seem to imply that $A u$. anamensis may have habitually engaged in arboreal activities and/or hand-assisted bipedality in either a terrestrial [Hunt, 1994] or an arboreal context [Thorpe et al., 2007]. Conversely, the findings for Au. afarensis do not indicate habitual arboreal behaviours. Rather, once the MCII facet became increasingly incorporated onto the distal capitate joint surface, as in KNM-WT 22944, the greater proportion of load directed towards the radial aspect increased even further through the arrangement of trabeculae. This combined effect of external and internal morphology is most pronounced in the capitate of the dexterous modern human hand. Taken to its logical conclusion, the results of our preliminary study seem to suggest that a behavioural shift in habitat exploitation occurred between $A u$. anamensis and $A u$. afarensis.

\section{Conclusion}

This pilot study assessed the changes in load transfer through capitates as a result of trabecular arrangement. An appraisal of the combined effects of internal and external bone shape is primarily of heuristic value for palaeobiomechanical research. Developmentally and phylogenetically constrained capitates were selected for analyses; these bones also have the potential to provide insights into the adaptations and evolutionary processes underlying the evolution of the hominin wrist. Particular focus was on the positional/locomotor behaviour of Au. anamensis and Au. cf. afaren- 
sis with a view to shed light on propositions that early hominins may have retained the plesiomorphic features of the upper limb by stabilizing selection.

Despite numerous limitations pertaining to experimental set-up, model creation and sample size, the results of this exploratory study are encouraging: they highlight the importance of trabeculae in load transfer. The differential between homogeneous and heterogeneous models was particularly marked in Pongo (28\%). Importantly, a common pattern of load transfer emerged with regard to broad positional/locomotor categories, irrespective of differences in outer morphology of the capitates and phylogenetic divergence of the species: arboreal species (Pongo, Pan) tend to redirect loads toward the ulnar aspect of the bone with the introduction of trabeculae, whereas more terrestrial species (Gorilla) and those with increased manipulatory capabilities (Homo) redirect loads towards the radial aspect. Against this backdrop, the manipulatory capabilties of the extinct $T$. oswaldi could be confirmed. Significantly, the results suggest that $A u$. anamensis habitually engaged in arboreal activities, while $A u$. cf. afarensis probably did not.

\section{Acknowledgments}

We thank Dr. Emma Mbua and the Trustees of the National Museum of Kenya for access to the fossil capitates, Dr. A. Kitchener for lending us the comparative material for scanning at the University of Liverpool, and Dr. H. Kiratisaeve for help with the mechanical testing of the capitate. This study was funded by the Leverhulme Trust (F/00 569/C).

\section{References}

Abel RL, Macho GA (2011). Ontogenetic changes in the internal and external morphology of the ilium in modern humans. Journal of Anatomy.

Carlson KJ, Patel BA (2006). Habitual use of the primate forelimb is reflected in the material properties of subchondral bone in the distal radius. Journal of Anatomy 208: 659-670.

Cartmill M, Milton K (1979). The lorisiform wrist joint and the evolution of 'brachiating' adaptations in the Hominoidea. American Journal of Physical Anthropology 47: 249-272.

Ciochon RL (1994). Evolution of the Cercopithecoid Forelimb: Phylogenetic and Functional Implications from Morphometric Analyses. Geological Sciences 138. Berkeley, University of California Press.

Cunningham CA, Black SM (2009a). Development of the fetal ilium - challenging concepts of bipedality. Journal of Anatomy 214: 91-99.

Cunningham CA, Black SM (2009b). Anticipating bipedalism: trabecular organization in the newborn ilium. Journal of Anatomy 214: 817-829.

Dainton M, Macho GA (1999a). Heterochrony: somatic, skeletal and dental development in Gorilla, Homo and Pan. In Growth in the Past: Studies from Bones and Teeth (Hoppa R, Fitzgerald C, eds.), pp 32-64. Cambridge, Cambridge University Press.

Dainton M, Macho GA (1999b). Did knuckle walking evolve twice? Journal of Human Evolution 36: 171-194.

Drapeau MSM, Ward CV (2007). Forelimb segment length proportions in extant hominoids and Australopithecus afarensis. American Journal of Physical Anthropology 132: 327-343.

-Gebo DL (1996). Climbing, brachiation, and terrestrial quadrupedalism: historic precursors of hominid bipedalism. American Journal of Physical Anthropology 101: 55-92.

Huiskes HWJ (2000). If bone is the answer, then what is the question? Journal of Anatomy 197: 145-156.

Hunt KD (1994). The evolution of human bipedality: ecology and functional morphology. Journal of Human Evolution 26: 183-202.

- Inouye SE (1994). Ontogeny of knuckle-walking hand postures in African apes. Journal of Human Evolution 26: 459-485. 
Jablonski NG, ed. (1993). Theropithecus: The Rise and Fall of a Primate Genus. Cambridge, Cambridge University Press.

Jenkins FA (1981). Wrist rotation in primates: a critical adaptation for brachiators. Symposia of the Zoological Society of London 48: 429-451.

Jenkins FA, Fleagle FR (1975). Knuckle walking and the functional anatomy of the wrists in living apes. In Primate Functional Morphology and Evolution (Tuttle RH, ed.), pp 213-227. The Hague, Mouton.

Jolly CJ (1972). The classification and natural history of Theropithecus (Simopithecus) (Andrews, 1916), baboons of the African Plio-Pleistocene. Bulletin of the British Museum (Natural History) Geology 22: $1-123$.

Kabel J, van Rietbergen B, Dalstra M, Odgaard A, Huiskes R (1999). The role of an effective isotropic tissue modulus in the elastic properties of cancellous bone. Journal of Biomechanics 32: 673-680.

Kivell TL, Schmitt D (2009). Independent evolution of knuckle-walking in African apes shows that humans did not evolve from a knuckle-walking ancestor. Proceedings of the National Academy of Sciences of the USA 106: 14241-14246.

Leakey MG, Feibel CS, McDougall I, Walker A (1995). New four-million-year-old hominid species from Kanapoi and Allia Bay, Kenya. Nature 376: 565-571.

Leakey MG, Feibel CS, McDougall I, Ward C, Walker A (1998). New specimens and confirmation of an early age for Australopithecus anamensis. Nature 393: 62-66.

Lewis OJ (1972). Osteological features characterising the wrists of monkeys and apes, with a reconsideration of this region in Dryopithecus (Proconsul) africanus. American Journal of Physical Anthropology 36: 45-58.

Lovejoy CO, Simpson SW, White TD, Asfaw B, Suwa G (2009a). Careful climbing in the Miocene: The forelimbs of Ardipithecus ramidus and humans are primitive. Science 326: 70e1-70e8.

Lovejoy CO, Suwa G, Simpson SW, Matternes JH, White TD (2009b). The great divides: Ardipithecus ramidus reveals the postcrania of our last common ancestors with African apes. Science 326: 100106.

Macho GA (2007). General principles of evolutionary morphology. In Handbook of Palaeoanthropology (Henke W, Rothe H, Tattersall I, eds.), vol 1: Principles, Methods, and Approaches, pp 769-785. Mainz, Springer.

Macho GA, Abel RL, Schutkowski H (2005). Age changes in bone microstructure: do they occur uniformly? International Journal of Osteoarchitecture 15: 421-430.

Manal K, Lu X, Nieuwenhuis MK, Helders PJM, Buchanan TS (2002). Force transmission through the juvenile idiopathic arthritic wrist: a novel approach using a sliding rigid body spring model. Journal of Biomechanics 35: 125-133.

Marzke MW (1971). Origin of the human hand. American Journal of Physical Anthropology 34: 61-84.

Marzke MW (1997). Precision grips, hand morphology, and tools. American Journal of Physical Anthropology 102: 91-110.

McColl DJ, Abel RL, Spears IR, Macho GA (2006). An automated method to measure trabecular thickness from micro-computed tomographic scans and its applications. Anatomical Record 288A: 982-988.

McHenry HM (1983). The capitate of Australopithecus afarensis and A. africanus. American Journal of Physical Anthropology 62: 187-198.

Patel BA (2010). The interplay between speed, kinetics, and hand postures during primate terrestrial locomotion. American Journal of Physical Anthropology 141: 222-234.

Rose MD (1988). Functional anatomy of the cheiridia. In Orang-Utan Biology (Schwartz JH, ed.), pp 299-310. Oxford, Oxford University Press.

Rose MR, Lauder GV, eds. (1996). Adaptation. San Diego, Academic Press.

Ryan TM, van Rietbergen B (2005). Mechanical significance of femoral head trabecular bone structure in Loris and Galago evaluated using micromechanical finite element models. American Journal of Physical Anthropology 126: 82-96.

Sarmiento EE (1988). Anatomy of the hominoid wrist joint: its evolutionary and functional implications. International Journal of Primatology 9: 281-345.

Schmitt D (2003). Mediolateral reaction forces and forelimb anatomy in quadrupedal primates: implications for interpreting locomotor behavior in fossil primates. Journal of Human Evolution 44: 47-58.

Taniguchi Y, Yoshida M, Iwasaki H, Otakara H, Iwata S (2003). Kienböck's disease in elderly patients. Journal of Hand Surgery 28: 779-783.

Thorpe SKS, Holder RL, Crompton RH (2007). Origin of human bipedalism as an adaptation for locomotion on flexible branches. Science 316: 1328-1331.

Tocheri MW, Marzke MW, Liu D, Bae M, Jones GP, Williams RC, Razdan A (2003). Functional capabilities of modern and fossil hominid hands: three-dimensional analysis of trapezia. American Journal of Physical Anthropology 122: 101-112. 
Tocheri MW, Orr CM, Larson SG, Sutikna T, Jatmiko, Saptomo EW, Due RA, Djubiantono T, Morwood MJ, Jungers WL (2007). The primitive wrist of Homo floresiensis and its implications for hominin evolution. Science 317: 1743-1745.

Turner CH, Rho J, Takano Y, Tsui TY, Pharr GM (1999). The elastic properties of trabecular and cortical bone tissues are similar: results from two microscopic techniques. Journal of Biomechanics 32: 437-441.

Tuttle RH (1967). Knuckle-walking and the evolution of hominoid hands. American Journal of Physical Anthropology 26: 171-206.

Tuttle RH (1969). Quantitative and functional studies on the hands of the Anthropoidea. 1. The Hominoidea. Journal of Morphology 128: 309-364.

Volpato V (2008). Morphogenèse de l'endostructure osseuse de l'ilion humain. Comptes Rendus de Palévolution 7: 463-471.

Volpato V, Viola TB, Nakatsukasa M, Bondioli L, Macchiarelli R (2008). Textural characteristics of the ilia-femoral trabecular pattern in a bipedally trained Japanese macaque. Primates 49: 16-25.

Ward CV (2002). Interpreting the posture and locomotion of Australopithecus afarensis: where do we stand? Yearbook of Physical Anthropology 45: 85-213.

Ward CV, Leakey MG, Brown B, Brown F, Harris J, Walker A (1999). South Turkwel: a new Pliocene hominid site in Kenya. Journal of Human Evolution 36: 69-95.

-Ward CV, Leakey MG, Walker A (2001). Morphology of Australopithecus anamensis from Kanapoi and Allia Bay, Kenya. Journal of Human Evolution 41: 255-368.

-White TD, Wolde Gabriel G, Asfaw B, Ambrose S, Beyene Y, Bernor RL, Boisserie J-R, Currie B, Gilbert H, Haile-Selassie Y, Hart WK, Hlusko LJ, Howell FC, Kono RT, Lehmann Y, Louchart A, Lovejoy CO, Renne PR, Saegusa H, Vrba ES, Wesselman H, Suwa G (2006). Asa Issie, Aramis and the origin of Australopithecus. Nature 440: 883-889. 